\title{
Set of Data Elements for Nautical Charts Cataloging: Analysis Between the RDA Scheme and the IDERA Metadata Profile
}

\author{
Edgardo Stubbs \\ Instituto de Investigaciones en Humanidades y Ciencias Sociales \\ (IDIHCS) FAHCE. UNLP- CONICET, Buenos Aires. Argentina.
}

\begin{abstract}
The nautical chart is a cartographic resource designed to meet the requirements of maritime navigation, showing the depth of the water and the nature of the seabed, as well as the configuration, features and elevation of the coast and the dangers and aids to navigation. The nautical charts provide a graphic representation of the information required by the navigator to carry out safe navigation. The organization and description of this type of resources is a key element when accessing information. From the scope of librarianship, the current scheme for the processing of information is the RDA standards Resource, description and access), which allow the description of all kinds of information resources. On the other hand, geospatial organizations have developed different specific metadata schemes for the processing of spatial information. Metadata allows a producer to describe a dataset fully so that users can understand the assumptions and limitations and evaluate the dataset's applicability for their intended use. In Argentina, the scheme for processing this kind of information is called IDERA, which is based on the ISO 19115: Standards on geographic information. The present work analyzes the treatment that specific rules of metadata like IDERA and general norms of description of resources like RDA give to the set of specific data present in the digital nautical charts. Methodology: from the identification of data elements that allow to describe and identify nautical charts as information resources a comparative table between both schemes was developed. Results: Neither of the two schemes has contemplated the totality of data element set established for the identification of nautical charts. The RDA scheme managed to better satisfy the description and identification of nautical charts that IDERA, although neither of them contemplate $100 \%$ the established data elements set. Conclusions and recommendations: 1) According to the above, neither of the two schemes to process the information complies in its entirety with the information contained in the nautical charts. 2) Some data elements do not fit in any of the two schemes, reducing visibility and information retrieval of the two schemes for processing information, RDA are those that allow a more complete description of the resource, although in a general, non-specific way. 3) The specialized spatial data scheme (IDERA) leaves out important data elements of this kind of resources. 4) IDERA metadata profile, although it was thought for spatial data does not include the special characteristics of the different resources that make it up. 5) It is advisable to develop a metadata profile that, in addition to contemplating the general characteristics of geospatial resources, includes the particularities of each class of its resources
\end{abstract}

Keywords: Nautical Charts - Metadata - Elements data set - Information retrieval - Information processing - RDA

\section{Introduction}

The nautical charts are an essential information resource for safe navigation. The nautical charts, however, are not only a useful resource for navigators; according to the International Hydrological Organization (OHI), they fulfil essentially two functions: 1) Maritime navigation, since most hydrographic services have the obligation to provide coverage of nautical charts of its national waters to the extent and at the scales where the safety of navigation of all types of ships, from the smallest to the largest, in all coastal waters, including important ports, visited by larger ships, and smaller sea arms of purely local interest. In this sense -the best known- nautical charts are navigation tools, and 2) as a source of information, since the national nautical charts present a detailed configuration of the seabed. In this sense, the national hydrographic services have a similar responsibility with respect to their jurisdictional waters to that of the cartographic organisms for terrestrial areas. Information about the shape of the seabed is required by a diversity of national users in addition to the 
navigators; for example, engineers interested in onshore construction, dredging contractors, oceanographers, defence agencies, coastal zone managers, etc.

These two functions mentioned above led to the national nautical charts, ie those nautical charts that represent marine spaces of national jurisdiction, that the series of national charts cover national waters in great detail. This situation is reflected in the very large scales used for the port plans and the general existence of at least two continuous coastal series: one large scale relatively large and the other slightly smaller.

Essentially we can identify three classes of nautical charts of national jurisdiction determined at the same time by the scale and the maritime space represented. These are letters from ports or portulans, from landings and coastal charts.

The concept of an international nautical chart emerged in 1967, as a need to provide the same safety in navigation in international waters. Since no country has jurisdiction over this type of chart, a commission constituted within the IHO established an exhaustive set of cartographic specifications to be used in the preparation of medium- and large-scale international charts, which became large progress in standardizing them. As a result of this activity, the international nautical charts covered all navigation charts. On the other hand, bilateral agreements were established between nations for the production of international nautical charts.

In this way, the development of international nautical charts evolved, adding two more classes to those already described: nautical charts of seagoing and oceanic nautical charts

The nautical charts are classified in; ports, seagoing, coastal, landings and oceanic. Being the first three of national jurisdiction and the last international one.

There are nautical charts in analog format, such as paper charts, or digital charts, and they can be obtained from various sources, official and private. Among the digital nautical charts we can differentiate two classes: nautical raster charts and nautical vector charts. The first ones are generated from the printed matrix, there being no difference with them. Vector nautical charts are developed from the superposition of information planes generating greater interception of the document with the user.

From the above it can be inferred that there is an important variety of users who consult and require nautical charts according to different information needs One of the essential tools for accessing this kind of resources are catalogues and other secondary documents that constitute the first step in accessing information resources. That is, the catalogue is the first element of selection that the user has when looking for information resources

According to the international cataloguing principles (2017) the objectives of the catalogue are:

to find bibliographic resources in a collection as the result of a search using attributes or relationships of the entities

to identify a bibliographic resource or agent (that is, to confirm that the described entity corresponds to the entity sought or to distinguish between two or more entities with similar characteristics)

to select a bibliographic resource that is appropriate to the user's needs (that is, to choose a resource that meets the user's requirements with respect to medium, content, carrier, etc., or to reject a resource as being inappropriate to the user's needs)

to acquire or obtain access to an item described (that is, to provide information that will enable the user to acquire an item through purchase, loan, etc., or to access an item electronically through an online connection to a remote source); or to access, acquire, or obtain authority data or bibliographic data

to navigate and explore

So any instrument that results from the processing of information must comply with these requirements. In general, the cartographic resources and in particular the nautical charts have been processed from two different kinds of regulations. Those generated from librarianship and information science (AACR2, RDA) and those developed in spatial information contexts (ISO 19115, IDERA, etc.). The former can be characterized as norms for the processing of general information, 
since they have not been thought to process exclusively cartographic data. The second are rules to process cartographic information exclusively.

\section{Idera metadata}

IDERA is an implemented standard for the description, documentation and cataloguing of spatial information resources used in the IDERA project, and recommended for use in other public and private areas of Argentina. It has been developed for vector data processing using the ISO 19115 standard and the ISO 19139 technical application as a basis.

In this standard, five classes identified by the letters A, B, C, D and E have been defined, adopting the following criteria:
A. Identification Information
B. Spatial Reference System
C. Distribution Information
D. Data Quality Information
E. Metadata information

On the other hand, each element can be mandatory, optional or conditional. In the first case the geographic metadata element must be present. In the second one it may or may not be present, at the discretion of the producer of the data set and for the case that it is a conditional element implies that the geographic metadata element must be present if the data set exhibits the characteristics defined by the element.

\section{RDA standart}

Resource Description and Access (RDA) is an international standard for cataloguing resources developed from the field of librarianship and information sciences. As proposed by Andrew, Moore and Larsgaard (2015) the RDA was developed with an eye to bringing library metadata into the wider data universe.

According to the exposed one of the most important differences between RDA and IDERA is the general character of one and the specific approach of another. Apart from these differences, the two standards must give satisfactory answers when processing cartographic resources. Although of course this expectation is greater specificity in the treatment of information by metadata

\section{Objective}

know how the analysed standards fit to the nautical charts processing needs from the analysis of the data elements defined for this kind of resources

\section{Methodology}

To carry out this research, two steps have been proposed

1) Identify the set of data elements that allow to represent and identify the content of the resource. For this purpose, different kinds of resources have been analysed, such as the nautical charts and complementary bibliography developed by the International Hydrological Organization in order to identify all those elements that may be used to represent the resource in question.

2) Once the set of data elements for the nautical charts has been defined, the capacity of each analysed rule (RDA, IDERA) to process and represent each of the data elements defined in the first step is analysed.

\section{Results}

In order to achieve a clearer presentation of the results, the data elements will be grouped in different tables with the purpose of achieving greater clarity in the visualization.

\begin{tabular}{|l|l|l|l|l|}
\hline \multirow{2}{*}{$\begin{array}{l}\text { Nautical Chats Data } \\
\text { element }\end{array}$} & RDA & \multicolumn{2}{|l|}{ IDERA } \\
\cline { 2 - 5 } & instruction & Name & ID & Name \\
\hline \multirow{3}{*}{ Title } & $2.3 .2 .1 / 8$. & Title proper & A.1 & Title \\
\cline { 2 - 3 } & 2.3 .2 .8 .2 & Title include scale & \\
\cline { 2 - 3 } & 2.3 .2 .11 .2 & Title for cartographic resource & & \\
\hline
\end{tabular}




\begin{tabular}{|c|c|c|c|c|}
\hline & 2.3 .4 .5 & $\begin{array}{l}\text { Complementary information } \\
\text { title for cartographic resource }\end{array}$ & & \\
\hline $\begin{array}{l}\text { Statement of } \\
\text { responsibility }\end{array}$ & 2.4 & Statement of responsibility & A.6 & Contact of data creator \\
\hline \multirow[t]{3}{*}{ Scale statement } & 7.25 .1 & Scale record & A.13 & \multirow[t]{3}{*}{ Scale } \\
\hline & 7.25 .3 & $\begin{array}{l}\text { Horizontal scale of the } \\
\text { cartographic content }\end{array}$ & & \\
\hline & 7.25 .4 & $\begin{array}{l}\text { Vertical scale of the } \\
\text { cartographic content }\end{array}$ & & \\
\hline Cartographic projection & 7.26 .1 & $\begin{array}{l}\text { Record of the projection of the } \\
\text { cartographic content }\end{array}$ & B.1 & Projection \\
\hline \multirow[t]{3}{*}{ Cartographic coordinates } & 7.4 .1 & $\begin{array}{l}\text { Record of the coordinates of } \\
\text { the cartographic content }\end{array}$ & \multirow[t]{3}{*}{ A17 } & \multirow[t]{3}{*}{ geographical extension } \\
\hline & 7.4 .2 & Latitude and longitude & & \\
\hline & 7.4 .3 & Chains of coordinate pairs & & \\
\hline
\end{tabular}

Table 1. Analyses five data elements that, while common to all cartographic resources, allow for some differences between the two standards considered

\section{Title}

RDA establishes a set of three instructions considering a wide range of possibilities according to the characteristics of the resource analyzed, including the scope, sources of information, form of registration, etc. (instructions 2.3.2.1-8) Also as shown in the table considers certain situations such as when the scale is included in the title (instruction 2.3.8.2), description of the title for cartographic resources (2.3.2.11.2), complementary information for cartographic resources. IDERA for its part for the title establishes some guidelines but always of a general nature, recommending that it does not exceed 50 characters, that it does not include acronyms or abbreviations and that it represents as faithfully as possible the content of the resource

\section{Statement of responsibility}

RDA establishes a set of possibilities for the registration of the statement of responsibility framed in instruction 2.4. Instruction 2.4.1 indicates how to record the statement of responsibility, 2.4.1.2 establishes sources of information. Instruction 2.4.1.5 establishes the criteria for cases where there is more than one person for the statement of responsibility and instruction 2.4.1.6 in cases where there is more than one mention of responsibility. Instruction 2.4.2 establishes the scope, sources of information and registration for the mentions of responsibility related to the proper title. IDERA in the field A6 establishes the instructions for the creator of the resource, being able to be an organism, institution or person responsible for it. Indicates that the surname should be loaded first and then the name of the creator in the case of people. If they were more than one, they should be separated by a comma (,). It does not establish any instruction for the case of organisms or institutions

\section{Scale statement}

RDA proposes a set of instructions for the registration of scale data. The set of instructions 7.25 .1 for the registration of the scale includes the scope (instruction 7.25.1.1), information sources (725.1.2) and the scale register (725.1.3). Instruction 7.25.1.4 considers the cases that there is more than one scale and instruction 7.25.1.5 establishes the criteria for recording those non-linear scales. The set of instructions 7.25.3 establishes the scope, sources of information and records of those horizontal scales of cartographic content. The vertical scale of cartographic content including the scope, sources of information and registration is contemplated in instruction 7.25.4. IDERA establishes the instructions for the scale in field A13 (ID13). The data must refer to the scale at which the terrestrial phenomena in the developed resource have been represented. It does not provide any specification or recommendation for the different scales that could be presented and only indicates the way to register. 


\section{Cartographic projection}

The set of instructions 7.26 establish the criteria for the registration of cartographic projections in RDA including the scope (7.26.1) information sources (7.26.2) and the registry (7.26.3). The set of instructions 7.27 allows to record any other detail of the cartographic content not contemplated in previous instructions. IDERA in field B.1 establishes the instructions for the map projection data. In order to standardize the data load in this field, IDERA proposes to use a set of geodetic parameters developed by the European Petroleum survey group that contains ellipsoids, datum, coordinate systems, cartographic projections, etc.

\section{Cartographic coordinates}

The set of instructions 7.4.1 refers to the registration of the coordinates of the cartographic content, including the scope (7.4.1.1), sources of information (7.4.1.2) and registration (7.4.1.3). Instruction set 7.4.2 establishes the criteria for longitude and latitude data. The instruction 7.4.2.1 the scope, 7.4.2.2 sources of information and 7.4.2.3 the record. The set of instructions 7.4.3 establishes the criteria for the registration of chains of coordinate pairs. IDERA considers in the field A17 under the name of geographic extension data of latitude and longitude.

RDA instruction 7.27 allows to record any other detail of the cartographic content not contemplated in previous instructions.

RDA establishes that the title proper, the mention of responsibility related to the title proper and the scale are core elements. IDERA

IDERA establish the title proper and the statement of responsibility are core elements. The scale and the geographic extension are optional data. The data of cartographic coordinates is conditional

\begin{tabular}{|c|c|c|c|c|}
\hline \multirow{2}{*}{$\begin{array}{l}\text { Nautical Chats Data } \\
\text { element }\end{array}$} & \multicolumn{2}{|l|}{ RDA } & \multicolumn{2}{|l|}{ IDERA } \\
\hline & Instruction & Name & Instruction & Name \\
\hline \multirow[t]{4}{*}{ Edition Statements } & 2.5 .1 & Edition statement record & \multirow[t]{4}{*}{ A.3, D.1 } & \multirow[t]{4}{*}{ Edition, lineage } \\
\hline & 2.5 .2 & Designation of edition & & \\
\hline & 2.5 .4 & $\begin{array}{l}\text { Statement of responsibility } \\
\text { relating to the edition }\end{array}$ & & \\
\hline & 2.5 .6 & $\begin{array}{l}\text { Designation of a named } \\
\text { revision of an edition }\end{array}$ & & \\
\hline \multirow{2}{*}{$\begin{array}{l}\text { Nautical Chats Data } \\
\text { element }\end{array}$} & \multicolumn{2}{|l|}{ RDA } & \multicolumn{2}{|l|}{ IDERA } \\
\hline & Instruction & Name & Instruction & Name \\
\hline \multirow[t]{4}{*}{ Production } & 2.7 .1 & Production statement & & \\
\hline & 2.7 .2 & Place of production & & \\
\hline & 2.7 .4 & Producer name & & \\
\hline & 2.7 .6 & Date of production & A.2.1 & Creation date \\
\hline \multirow[t]{4}{*}{ Publication } & 2.8 .1 & Publication statement & & \\
\hline & 2.8 .2 & Place of publication & & \\
\hline & 2.8 .4 & Publisher name & A.7 & Publisher name \\
\hline & 2.8 .6 & Publication date & A.2.1 & Publication date \\
\hline \multirow[t]{4}{*}{ Distribution } & 2.9 .1 & Distribution statement & & \\
\hline & 2.9 .2 & Place of distribution & & \\
\hline & 2.9 .4 & Distributor name & & \\
\hline & 2.9 .6 & Distribution date & & \\
\hline
\end{tabular}




\begin{tabular}{|l|l|l|l|l|}
\hline Manufacture & 2.10 .1 & Manufacture statement & & \\
\cline { 2 - 5 } & 2.10 .2 & Place of manufacture & & \\
\cline { 2 - 5 } & 2.10 .4 & Manufacturer name & & \\
\hline & 2.10 .6 & Manufacturing date & & \\
\hline Copyright date & 2.11 .1 & Copyright date statement & & \\
\hline
\end{tabular}

Table 3 shows two sets of data elements "Edition statement" and "production, publication, distribution, manufactures and copyright date".

\section{Edition Statements}

RDA allows to describe data about the edition mention from four sets of instructions. Edition statement record (2.5.1), including the scope (2.5.1.1) information sources (2.5.1.2) and the registry (2.5.1.4). Instruction set 2.5.2 establish the criteria for the designation of the edition including the scope, Is source of information and the record of the edition among others. Instructions sets 2.5.4 allows to describe in the case that the edition is related to the statement of responsibility including the scope (2.5.4.1), information sources (2.5.4.2) and the registry (2.5.4.3). The last instruction in this work related with edition statement is a Designation of a named revision of an edition (2.5.6) including the scope (2.5.6.1), information sources (2.5.6.2) and the registry (2.5.6.3)

IDERA, on the other hand in field A.3, allows to describe data related to edition statement. it could include data on the version of the resource, any change that may occur in the resource. It is a free text field restricted to 30 characters. In field D.1 (lineaje) allows to describe the sources of information from which it derives or from which the resource has been generated under documentation. This field can be matched with the instruction set 2.5.6 "designation of a named revision of an edition"

\section{Production, publication, distribution, manufacture and copyright date}

For each of the data elements (production, publication, distribution, manufacture and copyright data) RDA establishes a set of instructions for its description with a general character scheme except for the copyright date. In this way the instructions 2.7.2, 2.8.1, 2.9.1 and 2.10.1 allow to describe data related to production statement, publication statement, distribution statement and manufacture statement. For each case, instructions have been included that establish the scope, the sources of the information and the form of registration of the data. For the copyright date, the instruction 2.11.1 establishes the basic criteria for the registration of the copyright date including the scope (2.11.1), source of information (2.11.2) and the registration (2.11.3)

For these data elements, IDERA has developed three data fields that include that includes dates related to the production, creation or update of resources (A.2.1, A2.2) and the data field A.7 in which it is possible to describe the publisher name of the resource. A.2.1 named refence date. It is the field in which a date must be transcribed that can be of actualization, creation or production of the resource. The data field A.2.2 called Type of reference date. The type of date varies from publication creation and / or revision. But there can not be two of the same.

\begin{tabular}{|c|c|c|c|c|}
\hline \multirow{2}{*}{$\begin{array}{l}\text { Nautical Chats Data } \\
\text { element }\end{array}$} & \multicolumn{2}{|l|}{ RDA } & \multicolumn{2}{|l|}{ IDERA } \\
\hline & Instruction & Name & Field & Name \\
\hline \multirow[t]{2}{*}{ Physical description } & 3.4 .2 & $\begin{array}{l}\text { Extent of cartographic } \\
\text { resources }\end{array}$ & & \\
\hline & 3.5 .2 & $\begin{array}{l}\text { Dimensions of cartographic } \\
\text { resources }\end{array}$ & & \\
\hline \multirow{8}{*}{$\begin{array}{l}\text { Format and coding of } \\
\text { information }\end{array}$} & 3.1 .5 & Resources on line & C.1,C.3, C.4 & Link (name and description) \\
\hline & 3.3 .1 & Type of resource & A.12 & Type of resource \\
\hline & 3.19 .1 & feature of the digital file & A.15 & set of data characters \\
\hline & 3.19 .2 & type of file & & \\
\hline & 3.19 .3 & Format coding & & \\
\hline & 3.19 .5 & digital image resolution & & \\
\hline & 3.19 .8 & $\begin{array}{l}\text { digital representation of the } \\
\text { cartographic content }\end{array}$ & & \\
\hline & 3.20 .1 & System requirements & & \\
\hline
\end{tabular}

Table 3 shows two sets of data elements related to each other: "physical description" and "format and coding of information". 
Physical description defined by RDA includes extent of cartographic resources and dimensions of cartographic resources. The first case RDA developed different instructions for the description of the extension of the cartographic resource that includes its application (3.4.2.1) and the registry that includes a set of cartographic elements (3.4.2.2). The other set of elements, dimensions of cartographic resources included different cases to describe the size of cartographic materials (instructions 3.52.1-7), all in print format.

IDERA, on the other hand, has not defined any element of data for the physical description. In the case of the dimensions it is logical since they are described for printed formats. But it also does not offer options when describing the extension of the resource. At this point RDA, although it offers a set of different names of cartographic materials, is not the term nautical chart. Anyway the instruction 3.4.2.2 allows adding a name if none adapts to the resource that is described.

For the set of data element "format and coding of information" RDA has defined a set of instructions. The type of support including the scope (instruction 3.3.1.1), source of information (3.3.1.2) and instructions for registering the type of support. The set of instructions for feature of the digital file (3.19.1) allows to describe digital coding of a resource, although it is not specifically designed for cartographic resources, it includes it. Include the scope (19.1.1) source of information (3.19.1.2), record of feature of the digital file (3.19.1.3) and details of feature of the digital file (3.19.1.4). The set of instructions for type of file file (3.19.2) include the scope (19.2.1) source of information (3.19.2.2), Record of file type (3.19.2.3) and details of file type (3.19.2.4). In the same way RDA allows to describe format coding (3.19.3), digital image resolution (3.19.5), and System requirements (3.20.1) RDA establishes a set of specific instructions to describe the digital representation of the cartographic content (3.19.8) including the scope (3.19.8.1), the source of information (3.19.8.2), the registration of the digital representation of the cartographic content (3.19.8.3) and the registration of the digital representation of the cartographic content (3.19.8.4), which may include the type of data , the type of objects or the number of objects used to represent spatial information

In the IDERA metadata profile, only data about the online resource (fields C.1, C.3, C4), the type of resource (A.12) and the characteristics of the resource data set are included (A.15). Fields C1, C3, and C4 allow you to set Location for online access through the Uniform Resource Locator (URL) of the address or location of the resource, the name of the resource online, and a detailed textual description of what the online resource is respectively.

From the description of the set of data elements both in table two and three it is possible to infer that although the RDA is a scheme for the description of all kinds of resources, it delves into specific details covering in greater detail than the IDERA metadata profile

It is important to emphasize that the variety of instructions in each data set including recommendations, examples and in some cases suggestions of terms to use, contrasts with a relatively smaller number of instructions, and in many cases with the possibility of using the free From this comparison with both schemes one of the first inferences to which it can arrive is that in the IDERA metadata profile it is unlikely to achieve a standardized record given the number of subjective decisions that the scheme leaves to the person doing the description. RDA to establish a greater number of instructions for set of data elements reduces the range of variability improving the normalization of the description

\begin{tabular}{|c|c|c|c|c|}
\hline \multirow{2}{*}{$\begin{array}{l}\text { Nautical Chats Data } \\
\text { element }\end{array}$} & \multicolumn{2}{|l|}{ RDA } & \multicolumn{2}{|l|}{ IDERA } \\
\hline & Instruction & Name & Field & Name \\
\hline Subject & Undefined & & A.9 & Subject \\
\hline Abstract & 7.10 & Content summary & A.4 & Abstract \\
\hline Keywords & Undefined & & A.10 & Keys word \\
\hline \multirow[t]{2}{*}{ Language } & 6.11 & Expression language & \multirow[t]{2}{*}{ A.14 } & \multirow[t]{2}{*}{ Language } \\
\hline & 7.12 & Content language & & \\
\hline \multirow[t]{2}{*}{ Content } & $7.2-7.3$ & Content nature/ & \multirow[t]{2}{*}{ A.16 } & \multirow[t]{2}{*}{ Content extension } \\
\hline & 7.3 & content coverage & & \\
\hline $\begin{array}{l}\text { Restrictions on the } \\
\text { resource }\end{array}$ & 4.4 & Access restrictions & A.11 & $\begin{array}{l}\text { Restrictions on the } \\
\text { source }\end{array}$ \\
\hline expected audience & 7.7 .1 & expected audience & Undefined & \\
\hline
\end{tabular}

Table 4 shows aspects related to the description of the content of a resource such as the topic, summary and keywords; the language and issues related to access restrictions. 
From the point of view of the content description comparing each of the analysed aspects, the IDERA metadata profile offers greater possibilities when making the description. RDA does not include data elements for the subject and keywords. However, it allows incorporating keywords into the title of the mapping resource if the cataloguer deems it necessary for its description (Instruction 2.3.4.5).

The lack of some data elements related to the content description is due to the fact that in their conception the RDA would contemplate both the bibliographic description and the content in practice is still a pending element. This situation, it is important to say it comes from the previous standard for cataloguing, RDA. Naturally who applies this scheme at the time of doing the description of content will follow the instructions in the format that is working, for example Marc.

In relation to the language and in the restriction of access to the resource, RDA developed two instructions in the first case (6.11 and 7.12) and instruction (4.4) for the second. In the metadata profile IDERA presents the field A.14 in the first case and A.11 for the second. RDA establishes instruction 7.7.1 to describe the intended audience for the appeal. This data element is not defined in IDERA

\begin{tabular}{|l|l|l|l|l|}
\hline \multirow{2}{*}{ Nautical Chats Data element } & RDA & IDERA \\
\cline { 2 - 5 } & Instructión & Name & Field & Name \\
\hline Type of Nautical chart based on scale & Undefined & & Undefined & \\
\hline Type of nautical chart based on jurisdiction & Undefined & & Undefined & \\
\hline natural underwater dangers & Undefined & & Undefined & \\
\hline artificial submarine dangers & Undefined & & Undefined & \\
\hline identification of nautical charts & Undefined & & Undefined & \\
\hline Notice group to mariners & Undefined & & Undefined & \\
\hline standardization levels of nautical charts & Undefined & & Undefined & \\
\hline Rosas & Undefined & & Undefined & \\
\hline coast line & Undefined & & Undefined & \\
\hline Port types & Undefined & & Undefined & \\
\hline navigation aid & Undefined & & Undefined & \\
\hline Probes & Undefined & & Undefined & \\
\hline
\end{tabular}

Table 5 represents those sets of data elements of exclusive application for nautical charts not found in other type of cartographic resource.

None of the two schemes analyzed has developed instructions or fields for the description of the data elements considered in table 5. While some instructions (notes) in RDA can dump information is from a non-specific view, where the information is not standardized. The data elements defined for table 5 according to the RDA scheme make it difficult to retrieve the information. On the other hand, IDERA, despite being a metadata schema for cartographic resources, has not defined the data elements mentioned in this table either. Even no field, although not specific, has been found to describe the data

\section{Conclusion}

It is possible to analyze the results from two stages. First the results shown in tables 1.4. In them a greater level of detail can be observed by the RDA, assigning in most cases more than one instruction for the proposed data elements, thus achieving greater specificity and precision. As a result of this, allowing a high level of standardization in the description and at the same time minimizing the conceptual differences between the cataloguers when producing the data record. On the contrary of the RDA, each data element was linked in most cases with a single field defined in IDERA, leaving multiple options for the record by the cataloguer. Although this metadata profile is based on the Dublin Core and the norms ISI 19115 , the reduced number of fields cannot contemplate the general data elements that the nautical charts share with the rest of the cartographic resources.

This multiplicity of options left to the cataloguing criterion has a negative impact on the normalization of data.

The second stage of analysis is related to the data obtained in table 5. Both in the RDA and in the IDERA metadata profile there are instructions or fields that contemplate the set of specific data elements of the nautical charts. In a first view, it was expected to achieve greater efficiency in the specific spatial data scheme (IDERA) than the general scheme (RDA).

Thirty-two sets of data elements have been defined, of which RDA contemplates eighteen (56\%). IDERA considers fifteen $(46 \%)$. But doing a more exhaustive analysis the eighteen sets of data elements considered in the RDA include fifty 
instructions. On the other hand, the fifteen data elements included in the IDERA metadata profile include 21 fields. With what can be established that RDA uses 2.8 instructions for each data element and IDERA 1.4. From these data it can be concluded that RDA duplicates IDERA in completeness as a tool for the description of cartographic resources in general and nautical charts in particular

However, it must be borne in mind that of the thirty-two elements, twelve are specific to nautical charts and none of the two schemes have developed instructions for their description, apart from the possibility of being able to include the data elements in notes or other instructions of a general nature

It would be convenient to develop new versions so that both schemes incorporate instructions that allow the specific description of data elements defined for nautical charts, especially the IDERA metadata profile, which is a schema for describing spatial data.

\section{Bibliography}

[1] American Library Association, Canadian Federation of Library Associations and CILIP(c2016). RDA Toolkit. Disponible en: http://www.rdatoolkit.org/ [Último acceso: julio 2017]

[2] Comité Permanente para la Infraestructura de Datos Geoespaciales de las Américas (2013). Modelo de datos geoespaciales para las Américas. Versión 1. Río de Janeiro: CP-IDEA, 2013. Disponible en: http://www.unggimamericas.org/index.php/component/jdownloads/finish/80-manuales-yprincipales-diagnosticos/564modelo-de-datos-geoespaciales-de-las-americas2013?ttemid=0 [último acceso: julio 2017]

[3] Infraestructura de Datos Espaciales de la República Argentina (2014). Documento de Esquema de Metadatos de IDERA. Disponible en: http://www.idera.gob.ar/images/stories/downloads/estandares/Documento_de_ Esquema_de_Metadatos_IDERA_v1_0.pdf [último acceso: julio 2017]

[4] Stubbs, E.; Carut, C. (2017). Information processing analysis of the harbour nautical charts and their representation of the changes in the territory: the case of La Plata port. 13 International Conference on Social Science, 6 al 7 de octubre de 2017, Viena, Austria. EN: 13th International Conference on Social Sciences. Vienna: EUSER.

[5] Stubbs E; Carut, C; Gamba, V; Mendes, P.V.; Gutierrez, C; Medina, C; (2019) Descripcion de contenido en el procesamiento de las cartas naúticas. Rev. Interam. Bibliot. Medellin (Colombia) 42 (1) pp.35-42 [in press]

[6] Oliver, C (2010) Introducing RDA: a guide to the basis. Chicago: ALA. $124 \mathrm{p}$.

[7] Organizacion Hidrologica Internacional (2014) Reglamento de la $\mathrm{OHI}$ para cartas internacionales y especificaciones cartográficas de la OHI. Monaco: Bureau Hidrologico Internacional 